\title{
Childhood Abuse and its Relationship with Family Status, Gender, and Age in some Jordanian Schools
}

\author{
Linda Ahmad khateeb Hana'a H. Al fulfuli \\ Faculty of educational science, Isra University
}

\begin{abstract}
Background and Objective:is the period for children to confident and grow strong and with encouragement and love of their family and an extended society of caring adults. This study examined the relationships between childhood abuse, family status, gender and age in Amman, Jordan. Materials and Methods: sample of the study consisting 198 children (123 boys and 75 girls), aged between 8 and 16 years. Some of the participants were living with their fathers and mothers' others were living in special houses, with a single parent, or with relatives. Childhood Trauma Questionnaire- Short Form (CTQ- SF) is used in the study. Results: results indicated that the children living with their parents reported significantly less than those not living with their parents. No significant effects of gender were found on any of (CTQ) domains except the physical neglect. There were significant differences between children with age range (14-16) and children with smaller ages in all domains of (CTQ) in favor of older ages. Conclusion :the findings suggest that living far away from a normal family atmosphere is a strong variable affecting on developing childhood trauma.
\end{abstract}

Keywords: Childhood abuse, gender, family status, Jordanian schools.

DOI: $10.7176 / \mathrm{JEP} / 11-33-07$

Publication date: November $30^{\text {th }} 2020$

\section{Introduction}

Early developmental trauma (EDT) or childhood trauma may loosely be defined as any traumatic experience that occurs before 18 years of age (Bernstein and Fink, 1998). In more details, researchers had operationally defined childhood trauma(or Child maltreatment) as any experience of sexual abuse, physical abuse, physical neglect, emotional abuse, and emotional neglect, as measured by the Childhood Trauma Questionnaire (CTQ) (Kuo, Goldin, Werner, Heimberg, and Gross (2010). According to Malik, (2012), Child maltreatment might be defined as any behavior directed toward a child by an adult that endangers or impairs a child's physical or emotional health and development.

The United Nation's worldwide study on the abuse and violence against children (UNICEF, 2008) indicated 40 million children below the age of 15 suffer from abuse and neglect, requiring health and social care around the globe. Approximately 158 million children aged 5- 14 are engaged in child labor. An estimated 1.2 million children are trafficked every year. More than 1 million children worldwide are detained by law enforcement officials. Two million children are believed to be exploited through prostitution and pornography. US statistics suggest that more than 906,000 children werevictims of child maltreatment there in 2005, $61 \%$ experiencing neglect, $19 \%$ physical abuse, $10 \%$ sexual abuse, and $5 \%$ emotional andpsychological abuse. An estimated 1 out of 500 children died of theirmaltreatment, $36 \%$ from neglect, $28 \%$ from physical abuse, and $29 \%$ from multiple maltreatment types (US Department of Health and HumanServices, 2005).

It has been estimated that one in ten children, on average, is neglected or psychologically abused annually and that approximately $4 \%$ to $16 \%$ are physically abused. (Gilbert, Widom, Browne, Fergusson, Webb, Janson, 2008)In societies where use of force and violence are viewed as appropriatetechniques for suitable child rearing, problems related to this become astage set for child abuse, although these conditions also exist in the mostdeveloped countries like the United States (Belsky, 1980; Garbarino \& Vondra 1987).

Researchers have found that such childhood trauma has a fundamental, negative impact on adult psychological functioning (Bryer et al., 1987; Duncan et al., 1996; Fleming et al., 1999; Mullen et al., 1993, 1996). An examination of the relevant literature reveals that developmental delays, brain damage, learning disorders, depression, low academic achievement, speech disorders, poor peer relationships, inclination towards crime, alcohol and substance abuse, sleep disorders, eating disorders, low self-esteem, hyperactive or destructive/harmful behavior patterns, aggression, and fury appear in children and adolescents who have been exposed to abuse or neglect (Crozier \& Barth, 2005).

Child abuse and child neglect are problems that involve not only families but also social organizations, legal systems, the educational system, and business environments (Akduman, Ruban, Akduman, \& Korkmaz, 2005). Because neglect and abuse of children may recur, and these actions or inactions are performed on the children by their closest acquaintances, abuse and neglect have long-term effects on children that may continue for years. It is, therefore, vital that neglect and abuse are identified and treated ( Bahar, Savaş, \& Bahar, 2009). A loving and peaceful family environment, and healthy attitudes that the parents provide for the children, regulate children's behavior, social relationships, and their adaptation to society. Therefore, the behavior and attitudes that the parents 
display to their children, the environment in which the children grow up, the behavior of adults other than their parents around them, and the kind of communication that takes place in the family home are important for the children to develop a healthy personality (Bayhan, 1998). Childhood victimization is typically part of a matrix of environmental problems such as poverty, unemployment, parental alcohol and drug problems, and inadequate family functioning (Widom and White 1997; Kruttschnitt, McLeod, and Domfeld 1994).

Literatures review

There have a number of previous studies have been done around the world, investigated the relationship between child maltreatment and quality of life (QoL) in Norway. The study sample consisted of 335 adolescents living in residential youth care (RYC), 235 of them exposure to maltreatment others did not, and 1017 adolescents from general population used for comparison. This study reported that exposed adolescents in RYC reported poorer maltreatment than peers in control groups, i.e. childhood maltreatment was associated with a poorer QoL score(Greger, Myhre, Lydersen, and Jozefiak , 2016).Another study found that there was a positive relationship between physical abuse and negative social skills, a positive relationship between directing to crime and sexual abuse and negative social skills, and a positive relationship between neglect and emotional abuse and negative social skills (Saltali, 2012). Similarly, Di Pierro, Sarno, Perego, Gallucci, and Madeddu(2012) found that the selfinjurers were more impulsive, and aggressive than non-self-injurers and reported more sexual and physical abuse episodes than non-self-injurers. Also, Al-Sweeti (2012) reported that the students were faced with three kinds of violence from their families; i.e. psychological abuse, neglect, and physical abuse.

In another studies the results should that $96 \%$ from the children had emotional abuse, $84 \%$ had physical abuse, $59 \%$ had sexual abuse and 88\% had neglect (Madigan,Vaillancourt, Mckobbon\& Benoit, 2012). In Pakistan, Malik (2012) posits that the abuse children overall perceived their parents to be rejecting; severely abused children perceived more rejection. The results also revealed that contrary to the assumption, children scored higher on emotional abuse than on physical abuse. No gender differences were found on the level or type of abuse. Moreover, Nederlof, Van der Ham, Dingemans, and Oei (2010) found that the five maltreatment subtypes (measured by the Childhood Trauma Questionnaire) to be differentially and uniquely related to the normal and pathological personality dimensions in juvenile delinquents. Furthermore, Widom, Czajaand Paris (2009) indicated that significantly more abused and/or neglected children overall met criteria for BPD as adults, compared to controls, as did physically abused and neglected children.

In the last few years, there has been growing interest in investigations the childhood abuse in response effort of several foundations to curb this issue. Aforementioned phenomenon has become acritical predicament and thus hypothesized that childhood abuse negatively effects in personality and growth of children. The major aim of this study is to examined the relationships between childhood abuse, family status, gender and age, and to identify the possibility of influence of living far away from a normal family atmosphere on developing childhood trauma.

\section{Materials and Method Sample}

The data used in this study collected from Amman city schools. The sample were 198 children (123 boys and 75 girls), aged between 8 and 16 years $(M=11.98, S D=2.02)$. Some of the participants were living with normal families (i.e., with their fathers and mothers, $n=128$ ), others were not (i.e. they were living in special houses, with a single parent, or with relatives, $n=70$ ). They were in classes range between 3 and 11. Table (1) shows numbers and percentages of female and male participants in each group of children (children not living with their two parents, and children living with their two parents), and table (2) shows numbers and percentages of first group children across places that lived in, and gender variables.

\begin{tabular}{|c|c|c|c|}
\hline Group & Gender & $\mathbf{N}$ & $100 \%$ \\
\hline \multirow{3}{*}{ G1 } & Female & 18 & 25.7 \\
\hline & Male & 52 & 74.3 \\
\hline & Total & 70 & 100.0 \\
\hline \multirow{3}{*}{$\mathrm{G} 2$} & Female & 57 & 44.5 \\
\hline & Male & 71 & 55.5 \\
\hline & Total & 128 & 100.0 \\
\hline \multirow{3}{*}{ Total } & Female & 75 & 37.9 \\
\hline & Male & 123 & 62.1 \\
\hline & Total & 198 & 100.0 \\
\hline
\end{tabular}

G1: Children not living with their two parents, G2: Children living with their two parents. 
Table (2): Demographic of Children not living with their two parents

\begin{tabular}{cc|cc}
\hline Gender & Living status & $\mathbf{N}$ & $\mathbf{1 0 0} \%$ \\
\hline Female & Internal & 14 & 77.8 \\
& with father & 2 & 11.1 \\
& with mother & 2 & 11.1 \\
& with uncle, aunt & & 100.0 \\
\hline Tale & Total & 18 & 42.3 \\
& Internal & 22 & 15.4 \\
& with father & 8 & 11.5 \\
& with mother & 6 & 30.8 \\
& with uncle, aunt & 16 & 100.0 \\
\hline
\end{tabular}

\section{Measure}

Childhood Trauma Questionnaire- Short Form (CTQ- SF) is used in the study. This is a 28-item, self-report inventory assessing three domains of childhood abuse (sexual, physical, and emotional) and two domains of childhood neglect (physical and emotional). The items are rated on a 5-point Likert-type scale (Bernstein \& Fink, 1998). In this study five items of sexual abuse were removed from the questionnaire, and the other items were rated on 3-point scale according to jury opinions.Bernstein and Fink (1998) used the following definitions to describe each subscale. Emotional abuse refers to verbal assaults on a child's sense of worth or well-being or any threatening behavior directed toward a child by an older person. Physical abuse refers to bodily assaults on a child by an older person, which pose a risk of, or result in, injury. Sexual abuse refers to sexual contact or conduct between a child and an older person, including explicit coercion. Emotional neglect refers to the failure of caretakers to provide basic psychological and emotional needs, such as love and support. Physical neglect refers to the failure to provide basic physical needs including food and shelter.

Results

Number and percentage of children in each level of trauma (Mild, Moderate, and Severe) across dependent variables (EA, PA, EN, PN, Total Sc) are presented in table (3). Mean and standard deviation of participants in the Childhood Trauma Questionnaire scores of each level of trauma across the dependent variables are also shown in this table, in addition to $(\mathrm{F})$ and $(\mathrm{P})$ values.

Table (3) Comparison of Dependent Variables across Mild, Moderate, and Severely Abused Children of all Participants $(n=198)$.

\begin{tabular}{|c|c|c|c|c|c|c|}
\hline Dependent Variable & Level & $\mathrm{N}$ & $\%$ & $\mathrm{M}(\mathrm{SD})$ & $\mathrm{F}$ & $P$ \\
\hline \multirow[t]{3}{*}{ EA } & Mild & 115 & 58.1 & $6.03(1.06)$ & 589.86 & .000 \\
\hline & Moderate & 72 & 36.4 & $10.15(1.00)$ & & \\
\hline & Sever & 11 & 5.6 & $14.45(.69)$ & & \\
\hline \multirow[t]{3}{*}{ PA } & Mild & 121 & 61.1 & $5.71(1.07)$ & 917.99 & .000 \\
\hline & Moderate & 53 & 26.8 & $10.04(.85)$ & & \\
\hline & Sever & 24 & 12.1 & $14.21(.78)$ & & \\
\hline \multirow[t]{3}{*}{$\mathrm{EN}$} & Mild & 90 & 45.5 & $6.14(1.16)$ & 673.58 & .000 \\
\hline & Moderate & 87 & 43.9 & $10.31(.94)$ & & \\
\hline & Sever & 21 & 10.6 & $14.29(.90)$ & & \\
\hline \multirow[t]{3}{*}{$\mathrm{PN}$} & Mild & 89 & 44.9 & $6.99(.86)$ & 614.67 & .000 \\
\hline & Moderate & 82 & 41.4 & $10.44(1.06)$ & & \\
\hline & Sever & 27 & 13.6 & $13.44(.64)$ & & \\
\hline \multirow[t]{3}{*}{ Total Sc } & Mild & 102 & 51.5 & $25.58(3.37)$ & 758.39 & .000 \\
\hline & Moderate & 73 & 36.9 & $40.04(3.27)$ & & \\
\hline & Sever & 23 & 11.6 & $52.43(4.04$ & & \\
\hline
\end{tabular}

Note. Children were categorized into 3 groups of mild, moderate and severely abused on the basis of their obtained score on Child Abuse Scale as per its predetermined criteria. EA=Emotional Abuse, $\mathrm{PA}=\mathrm{Physical}$ Abuse, EN= Emotional Neglect, PN= Physical Neglect, Total AN= Total Score of Abuse and Neglect, Gr1= Children not living with their two parents, Gr2= Children living with their two parents.

Results in table (3) show that children, generally, are ranked on abuse levels from mild, as a majority, to sever, as a minority in all domains of the Childhood Trauma Questionnaire and the total score. The results of one-way ANOVA show that the differences of the children's scores on all dependent variables are significant across the three trauma levels (mild, moderate and sever).

Table (4) reports the results when the same statistical procedures are conducted for each group of children (Children living and not living with their parents). 
Table (4) Comparison of Dependent Variables across Mild, Moderate, and Severely Abused Children in both Groups (Gr1, N=70; Gr2, N=128).

\begin{tabular}{|c|c|c|c|c|c|c|c|}
\hline Dependent Variable & Group & Level & $\mathrm{N}$ & $\%$ & $\mathrm{M}(\mathrm{SD})$ & $\mathrm{F}$ & $p$ \\
\hline \multirow[t]{5}{*}{ EA } & Gr1 & Mild & 16 & 22.9 & $6.38(.72)$ & 231.85 & .000 \\
\hline & & Moderate & 43 & 61.4 & $10.40(1.09)$ & & \\
\hline & & Sever & 11 & 15.7 & $14.45(.69)$ & & \\
\hline & Gr2 & Mild & 99 & 77.3 & $5.97(1.10)$ & 309.08 & .000 \\
\hline & & Moderate & 29 & 22.7 & $9.79(.73)$ & & \\
\hline \multirow[t]{5}{*}{$\mathrm{PA}$} & Gr1 & Mild & 22 & 31.4 & $5.77(.92)$ & 502.57 & .000 \\
\hline & & Moderate & 24 & 34.3 & $10.13(.99)$ & & \\
\hline & & Sever & 24 & 34.3 & $14.21(.78)$ & & \\
\hline & Gr2 & Mild & 99 & 77.3 & $5.70(1.10)$ & 384.64 & .000 \\
\hline & & Moderate & 29 & 22.7 & $9.97(.73)$ & & \\
\hline \multirow[t]{5}{*}{ EN } & Gr1 & Mild & 18 & 25.7 & $6.33(1.28)$ & 294.05 & .000 \\
\hline & & Moderate & 31 & 44.3 & $10.58(.92)$ & & \\
\hline & & Sever & 21 & 30.0 & $14.29(.90)$ & & \\
\hline & Gr2 & Mild & 72 & 56.3 & $6.10(1.13)$ & 475.34 & .000 \\
\hline & & Moderate & 56 & 43.8 & $10.16(.93)$ & & \\
\hline \multirow[t]{6}{*}{$\mathrm{PN}$} & Gr1 & Mild & 16 & 22.9 & $7.00(1.03)$ & 239.74 & .000 \\
\hline & & Moderate & 31 & 44.3 & $10.71(1.01)$ & & \\
\hline & & Sever & 23 & 32.9 & $13.52(.67)$ & & \\
\hline & Gr2 & Mild & 73 & 57.0 & $6.99(.82)$ & 243.02 & .000 \\
\hline & & Moderate & 51 & 39.8 & $10.27(1.06)$ & & \\
\hline & & Sever & 4 & 3.1 & $13.00(.00)$ & & \\
\hline \multirow[t]{6}{*}{ Total AN } & Gr1 & Mild & 19 & 27.1 & $27.47(3.53)$ & 268.20 & .000 \\
\hline & & Moderate & 29 & 41.4 & $42.59(3.05)$ & & \\
\hline & & Sever & 22 & 31.4 & $52.68(3.96)$ & & \\
\hline & Gr2 & Mild & 83 & 64.8 & $25.14(3.20$ & 320.87 & .000 \\
\hline & & Moderate & 44 & 34.4 & $38.36(2.15)$ & & \\
\hline & & Sever & 1 & .8 & $47.00(.00)$ & & \\
\hline
\end{tabular}

Note. Gr1= Children not living with their two parents, Gr2= Children living with their two parents.

As shown in table (4), sever trauma level is found among children not living with their parents in all domains of the Childhood Trauma Questionnaire and the total score. Meanwhile, sever trauma level did not appear among children living with their parents in all domains of the Childhood Trauma Questionnaire except in the physical neglect which included only four cases. Again, one-way ANOVA results show highly significant differences in all dependent variable across the three trauma levels (mild, moderate and sever).

In order to determine the differences across the two groups, $\mathrm{t}$ - test for independent samples was applied as presented in table (5).

Table (5) Comparison of Dependent Variables between both Groups of Children

\begin{tabular}{|c|c|c|c|c|c|c|}
\hline Dependent Variable & Groups & $\mathrm{N}$ & Mean & SD & $\mathrm{t}$ & Sig. \\
\hline \multirow{2}{*}{ EA } & Gr1 & 70 & 10.11 & 2.68 & 9.97 & .000 \\
\hline & Gr2 & 128 & 6.84 & 1.91 & & \\
\hline \multirow{2}{*}{ PA } & Gr1 & 70 & 10.16 & 3.55 & 8.75 & .000 \\
\hline & Gr2 & 128 & 6.66 & 2.07 & & \\
\hline \multirow{2}{*}{$\mathrm{EN}$} & Gr1 & 70 & 10.60 & 3.15 & 7.01 & .000 \\
\hline & Gr2 & 128 & 7.88 & 2.28 & & \\
\hline \multirow{2}{*}{ PN } & Gr1 & 70 & 10.79 & 2.58 & 6.10 & .000 \\
\hline & Gr2 & 128 & 8.48 & 2.01 & & \\
\hline \multirow{2}{*}{ Total AN } & Gr1 & 70 & 41.66 & 10.31 & 9.50 & .000 \\
\hline & Gr2 & 128 & 29.86 & 7.08 & & \\
\hline
\end{tabular}

.Gr1: Children not living with their two parents, Gr2: Children living with their two parents.

Results in table (5) show the influence of living far away from a normal family atmosphere on developing childhood trauma. All $(\mathrm{t})$ values in all domains of the Childhood Trauma Questionnaire and the total score reflected significant differences at $(\alpha \leq 0.05)$ in favor of children not living with their parents.

To determine the gender effect on childhood trauma, mean, standard deviation and t-test for independent samples on each domain of the Childhood Trauma Questionnaire and the total score were calculated, as shown in table (6) 
Table (6) Comparison of Dependent Variables between Girls and Boys

\begin{tabular}{|c|c|c|c|c|c|c|}
\hline Dependent Variable & Groups & $\mathrm{N}$ & Mean & SD & $\mathrm{t}$ & Sig. \\
\hline \multirow{2}{*}{ EA } & Girls & 75 & 7.68 & 2.41 & -1.28 & .202 \\
\hline & Boys & 123 & 8.19 & 2.87 & & \\
\hline \multirow{2}{*}{ PA } & Girls & 75 & 7.51 & 2.73 & -1.37 & .173 \\
\hline & Boys & 123 & 8.14 & 3.38 & & \\
\hline \multirow{2}{*}{$\mathrm{EN}$} & Girls & 75 & 8.55 & 2.23 & -1.10 & .273 \\
\hline & Boys & 123 & 9.02 & 3.26 & & \\
\hline \multirow{2}{*}{ PN } & Girls & 75 & 8.71 & 2.20 & -2.66 & .008 \\
\hline & Boys & 123 & 9.66 & 2.58 & & \\
\hline \multirow{2}{*}{ Total AN } & Girls & 75 & 32.44 & 8.166 & -1.74 & .083 \\
\hline & Boys & 123 & 35.00 & 10.10 & & \\
\hline
\end{tabular}

The results in table (6) show that there is no significant effect of gender on childhood trauma, except on physical neglect, i.e., $(\mathrm{t})$ values in all domains of the Childhood Trauma Questionnaire and the total score are significant except in the physical neglect domain.

Participants' ages were grouped into three categories (8-10, 11-13, 14-16). One-way ANOVA was used to determine the age effect on childhood trauma, the results are illustrated in table (7).

Table (7) Comparison on Dependent Variables between Age Ranges of Participants

\begin{tabular}{|c|c|c|c|c|c|c|}
\hline Dependent Variable & Age Range & $\mathrm{N}$ & $\%$ & $\mathrm{M}(\mathrm{SD})$ & $\mathrm{F}$ & $p$ \\
\hline \multirow[t]{3}{*}{ EA } & $8-10$ & 62 & 31.31 & $7.94(2.89)$ & 5.29 & .006 \\
\hline & $11-13$ & 88 & 44.44 & $7.48(2.44)$ & & \\
\hline & $14-16$ & 48 & 24.24 & $9.02(2.72)$ & & \\
\hline \multirow[t]{3}{*}{ PA } & $8-10$ & 62 & 31.31 & $7.76(3.07)$ & 4.76 & .010 \\
\hline & $11-13$ & 88 & 44.44 & $7.36(3.01)$ & & \\
\hline & $14-16$ & 48 & 24.24 & $9.06(3.29)$ & & \\
\hline \multirow[t]{3}{*}{ EN } & $8-10$ & 62 & 31.31 & $8.65(2.91)$ & 8.42 & .000 \\
\hline & $11-13$ & 88 & 44.44 & $8.20(2.61)$ & & \\
\hline & $14-16$ & 48 & 24.24 & $10.25(3.04)$ & & \\
\hline \multirow[t]{3}{*}{$\mathrm{PN}$} & $8-10$ & 62 & 31.31 & $8.50(2.31)$ & 16.82 & .000 \\
\hline & $11-13$ & 88 & 44.44 & $8.97(2.27)$ & & \\
\hline & $14-16$ & 48 & 24.24 & $10.94(2.36)$ & & \\
\hline \multirow[t]{3}{*}{ Total AN } & $8-10$ & 62 & 31.31 & $32.84(9.89)$ & 9.44 & .000 \\
\hline & $11-13$ & 88 & 44.44 & $32.01(9.28)$ & & \\
\hline & $14-16$ & 48 & 24.24 & $39.27(10.08)$ & & \\
\hline
\end{tabular}

All (F) values presented in table (7) are statistically significant at $(\mathrm{p}=0.01)$. That means the differences among age ranges are significant in all domains of the Childhood Trauma Questionnaire and the total score.

Post Hoc Scheffe test is used to determine which pair of comparisons was significant. Table (8) shows the pair comparisons that contain only significant differences.

Table (8)Results of Post hoc Scheffe Test of Pair Significant Differences.

\begin{tabular}{cccccc}
\hline Dependent Variable & (I)Age Range & M (SD) & (J)Age Range & M (SD) & p \\
\hline EA & $14-16$ & $9.02(2.72)$ & $11-13$ & $7.48(2.44)$ & .006 \\
PA & $14-16$ & $9.06(3.29)$ & $11-13$ & $7.36(3.01)$ & .011 \\
EN & $14-16$ & $10.25(3.04)$ & $8-10$ & $8.65(2.91)$ & .014 \\
& $14-16$ & $10.25(3.04)$ & $11-13$ & $8.20(2.61)$ & .000 \\
PN & $14-16$ & $10.94(2.36)$ & $8-10$ & $8.50(2.31)$ & .000 \\
& $14-16$ & $10.94(2.36)$ & $11-13$ & $8.97(2.27)$ & .000 \\
Total AN & $14-16$ & $39.27(10.08)$ & $8-10$ & $32.84(9.89)$ & .003 \\
& $14-16$ & $39.27(10.08)$ & $11-13$ & $32.01(9.28)$ & .000 \\
\hline
\end{tabular}

As shown in table (8), all pair comparisons are statistically significant at $(\mathrm{p} \leq 0.05)$. In other words, there were significant differences between children with age range (14-16) and children with smaller ages in all domains of (CTQ) in favor of older ages.

\section{Discussion and Future Recommendations}

This study aimed to investigate the relationships between child abuses, family status, gender and age in Amman, Jordan. Childhood Trauma Questionnaire-short Form (CTO- SF) is used in the study. Children were categorized into three groups, of mild, moderate, and severely abused on the basis of their obtained score. Results indicate that children generally, are ranked on abuse levels from mild, as a majority to sever, as a minority in all domains of the childhood Trauma, it was found that the young children to suffer more than older ages. However, there is no significant effect of gender on childhood Trauma, except on physical neglect domain. The above resultsbasically 
refer to chidern have a belief make them recognizes that the family'scontrol andcare is an abuse. This leads to negative attitudes formation towards familycare, where the revenge begins to avenge during instructions of violating and rebellionagainst laws to reach in their wishes and needs, also chidern considerthat their needs and desires are a basic need must be met by family, especially themother, where they expect a lot of compassion as a family duty.

\section{Limitations and Future Recommendations}

The above study new observation and contribution regarding climb on of our knowledge towards childhood abuse and its relationship with family status, gender, and age in some Jordanian schools, more over its recommend that future studies are advised to employ a large sample size and explore other independent variables,

\section{Conflicts of Interest}

The authors declare no conflicts of interest regarding the publication of this paper.

\section{References}

Akduman, G.G.; Ruban, C.; Akduman, B. \& Korkmaz, I. (2005). Child and sexual abuse. Journal of Forensic Psychiatry, 3, p. 9-14.

Al-Sweeti, A. (2012). Family violence directed towards children: its relation to security feeling for adolescents in Hebron city (in Arabic). Journal of Alazhar University in Ghazah, 14 (1), p. 281-310.

Bahar, G.; Savaş, A. H. \& Bahar, A. (2009). Child abuse and neglect: A review. Journal of Fırat Health Services, 4, p. 51-65.

Bayhan, P. (1998). The beaten child. Journal of Social Ministration, 1, p. 24-26.

Belsky, J. (1980). Child maltreatment: An ecological integration. American Psychologist, 35, 320-335.

Bernstein DP, Fink L (1998). Childhood Trauma Questionnaire: a Retrospective Self-Report Manual. San Antonio, TX: Psychological Corporation.

Bernstein DP, Fink L. (1998). Manual for the Childhood Trauma Questionnaire. New York: Psychological Corporation.

Bryer, J.B.; Nelson, B.A.; Miller, J.B. \&Krol, P.A. (1987). Childhood sexual and physical abuse as factors of adult psychiatric illness. Am J Psychiatry, 144, p.1426-1430.

Crozier, J. C. \& Barth, R. P. (2005). Cognitive and academic functioning in maltreated children. Children and Schools, 27, p. 197-206. Retrieved form: http://doi.org/hn8

Duncan, R.D.; Saunders, B.E. ; Kilpatric, D.G.; Hanson, R.F. \& Resnick, H.S. (1996). Childhood physical assault as a risk factor for PTSD, depression, and substance abuse: findings from a national survey. Am $J$ Orthopsychiatry, 66, p. 437-448.

Fleming, J.; Mullen, P.E.; Sibthorpe, B. \&Bammer, G. (1999). The long-term impact of childhood sexual abuse in Australian women. Child Abuse Negl, 23, p.145-159.

Garbarino, J., \& Vondra, J. (1987). Psychological maltreatment: Issues and perspectives. In M. R. Brassard, R. Germain,\& S. N. Hart (Eds.), Psychological maltreatment of children and youth. YN: Pergamon Press.

Gilbert R, Widom CS, Browne K, Fergusson D, Webb E, Janson S. (2008). Burden and consequences of child maltreatment in high- income countries.Lancet, 373, p. 68-81. DOI: 10.1016/S0140-6736(08)61706-7.)

Greger, H.K.; Myhre, A.K.; Lydersen, S.; Jozefiak, T. (2016). Child maltreatment and quality of life: a study of adolescents in residential care. Health Qual Life Outcomes, 14: 74, Retrieved from:https://www.ncbi.nih.gov/pmc/articles

Kruttschnitt, C.; McLeod, J.D. \& Domfeld, M. (1994). The economic environment of child abuse. Social Problems, 41, p. 299-315.

Kuo JR, Goldin PR, Werner K, Heimberg RG, Gross J.J. (2011). Childhood trauma and current psychological functioning in adults with social anxiety disorder. $J$ Anxiety Disord, 25(4), p. 467-473.

Malik, F. (2012) Parental Acceptance-Rejection and Paternal Authoritarianism among Abused Children

Mullen, P.E.; Martin, J.L.; Anderson, J.C.; Romans, S.E. \&Herbison, G.P. (1993). Childhood sexual abuse and mental health in adult life. Br J Psychiatry, 163, p. 721-732.

Mullen, P.E.; Martin, J.L.; Anderson, J.C.; Romans, S.E. \&Herbison, G.P. (1996). The long-term impact of the physical, emotional, and sexual abuse of children: a community study. Child Abuse Negl, 20, p.7-21.

Nederlof, E; Van der Ham, J.M; Dingemans, P.M.; and Oei, T.I (2010). The relation between dimensions of normal and pathological personality and childhood maltreatment in incarcerated boys. Journal of Personality Disorder, 24(6), p. 746-762.

U.S. Department of Health and Human Services. (2008). USA Federal Child Abuse Prevention and Treatment Act. Retrieved form: http://www.childwelfare.gov/can/defining/federal.cfm

UNICEF (2008). UN Secretary-General's study on violence against children. Retrieved from: www.savethechildren.net/alliance/resources/publications.html 
Widom, C. S.; Czaja, S. J. and Paris, J. (2009). A prospective investigation of Borderline Personality Disorder in abused and neglected children followed up into adulthood. Journal of Personality Disorders, 23(5), p. 433446.

Widom, C.S. \& Helene, R.W. (1997). Problem behaviors in abused and neglected children grown up: Prevalence and cooccurrence of substance abuse, crime and violence." Criminal Behavior and Mental Health, 1, p.2731. 